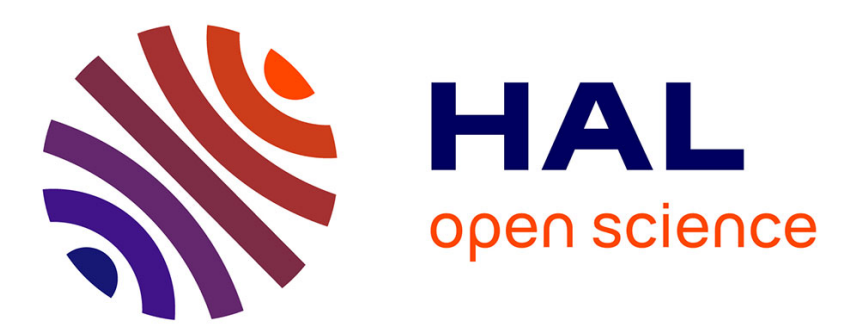

\title{
Water absorption in novolac epoxy resins studied by positron annihilation
}

T. Miura, T. Suzuki, Y. Oki, M. Numajiri, K. Kondo, Y. Shiomi, Y. Ito

\section{To cite this version:}

T. Miura, T. Suzuki, Y. Oki, M. Numajiri, K. Kondo, et al.. Water absorption in novolac epoxy resins studied by positron annihilation. Journal de Physique IV Proceedings, 1993, 03 (C4), pp.C4-249-C4252. 10.1051/jp4:1993437. jpa-00251480

\section{HAL Id: jpa-00251480 https://hal.science/jpa-00251480}

Submitted on 1 Jan 1993

HAL is a multi-disciplinary open access archive for the deposit and dissemination of scientific research documents, whether they are published or not. The documents may come from teaching and research institutions in France or abroad, or from public or private research centers.
L'archive ouverte pluridisciplinaire HAL, est destinée au dépôt et à la diffusion de documents scientifiques de niveau recherche, publiés ou non, émanant des établissements d'enseignement et de recherche français ou étrangers, des laboratoires publics ou privés. 


\title{
Water absorption in novolac epoxy resins studied by positron annihilation
}

\author{
T. MIURA, T. SUZUKI, Y. OKI, M. NUMAJIRI, K. KONDO, Y. SHIOMI* and Y. ITO**
}

National Laboratory for High Energy Physics, Radiation Control Center, Oho, Tsukuba, Ibaraki 305, Japan

${ }^{*}$ Tsukuba Research Laboratory, Sumitomo Chemical Co. LTD, Kitahara, Tsukuba, Ibaraki 300-32, Japan

${ }^{* *}$ Research Center for Nuclear Science and Technology, The University of Tokyo, Tokai, Ibaraki 319-11, Japan

\section{Abstract}

Water absorption rates of four kinds of epoxy resins cured with phenol novolac ( $\mathrm{PH}$ ) were compared with the results of positron annihilation lifetime measurements (PAL). Three samples: cresol novolac (CR), tetra-methyl-biphenol (TMB) and bis-phenol A (BA), showed almost similar absorption rates, while tris-hydroxy-phenyl-methane (THPM) absorbed water twice as fast as others. Since THPM has a larger $\tau_{3}$ value (hence larger intermolecular-space holes) than the other samples, the correlation between $\tau_{3}$ and the absorption rate seems evident. For THPM, the lifetime distribution was shifted toward a shorter lifetime after absorbing water, which is interpreted in terms of the particular structure of three-dimensional holes.

\section{Introduction}

Among many types of epoxy resins, novolac epoxy resins are widely used for encapsulation of Integrated circuits (ICS) in order to protect semiconductor chips and circuits from moisture, dusts, and other external obstructions, as well as to secure the electrical insulation. It is required for the encapsulation materials to have high mechanical strength, high moisture resistance, and high heat resistance. The present authors have applied PAL to study the characteristics of novolac epoxy resins used for ICs /1/, and microscopic information from PAL was compared with macroscopic characteristics obtained by standard methods: glass transition temperatures (Tg), thermal expansion coefficient, mechanical strength and water absorption rate.

In this work, the water absorption rate is discussed in detail and 1 ifetime distributions of $\tau_{3}$ are compared with three dimensional hole structures calculated using molecular dynamics method. 


\section{Experiment}

The positron annihilation experiments were conducted with a conventional fast-fast coincidence system with a time resolution of $270 p s$ full width at half maximum (FWHM).

Four kinds of epoxy resins: CR, THPM, TMB and BA, were cured with $\mathrm{PH}$, adding tri-phenyl-phosphin as a catalyst (these are kindly supplied from sumitomo Chemical Co. Ltd.). For the measurements of water absorption rate, the samples were immersed in a water bath controlled at about $98^{\circ} \mathrm{C}$ and a weight increase of $2.3 \%$ was obtained in 10 days: PAL measurements were conducted for $1 \mathrm{~h}$ to collect ca. 2 million events at each measurement of the water absorption rate. For the analysis of lifetime distribution, the samples were immersed for 4 months in the water bath to achieve ca. $3 \%$ weight increase and PAL data were collected more than $10 \mathrm{million}$ events from $6 \sim 7 \mathrm{~h}$ measurements. Although, during measurements, the samples were not sealed, the moisture content was not changed after and before PAL: water absorbed in samples is considered to be attached to hydrophilic radicals.

3. Results and discussion

3.1 Water absorption and positron annihilation results of $\mathrm{I}_{3}$ and $\tau_{3}$

Water absorption rate, defined by mass increase in weight $(\Delta M)$ within $1 \mathrm{~h}$ after immersing samples in water $\triangle M / M O$ (MO: original mass), was as follows: $0.47 \%, 0.88 \%, 0.46 \%$, and $0.45 \%$ for CR, THPM, TMB and BA, respectively. These results indicate that three samples: CR, TMB and BA, show almost similar absorption rates, while THPM absorbs water twice as fast as others. The relation between the weight increase and $\mathrm{I}_{3}\left(\tau_{3}\right)$ is shown in Figure 1 (2).

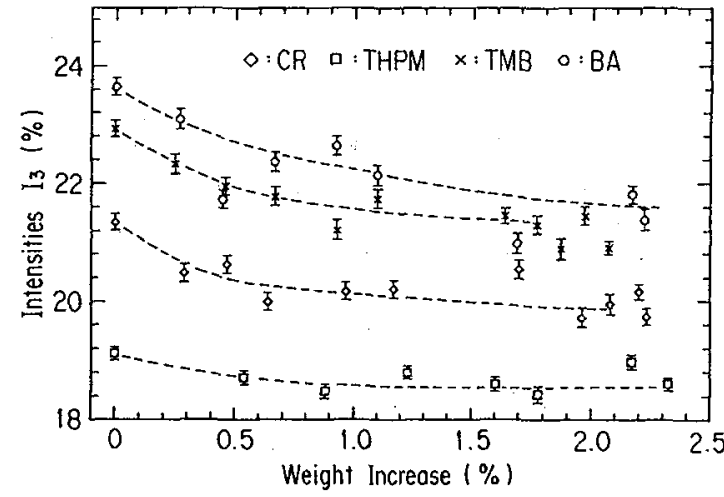

Figure $1, I_{3}$ vs water absorption

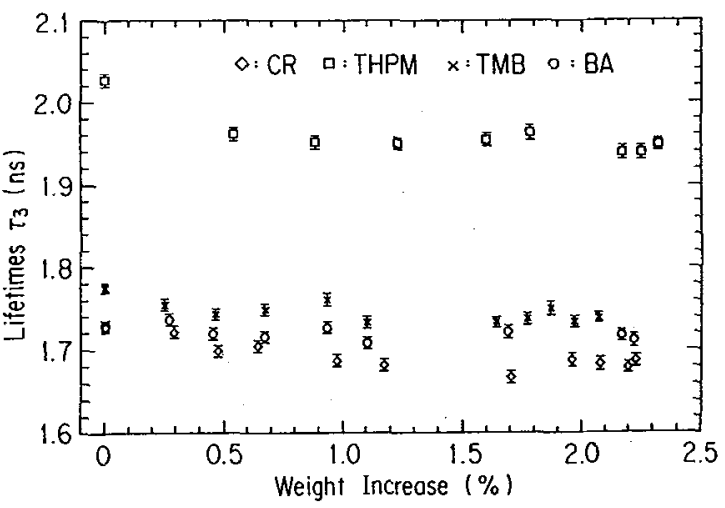

Figure $2, \tau_{3}$ vs water absorption 


\subsection{Distribution of $\tau_{3}$ and water absorption}

In the analysis of lifetime spectra using POSITRONFIT $/ 2 /$, the number of the lifetime components must be given as an input data. On the other hand, using a computer code "CONTIN" /3 7/, the lifetime spectra can be resolved into a smooth solution without knowing the number of the lifetime components. The CONTIN was applied to the lifetime spectra for the four kinds of novolac epoxy resins with and without

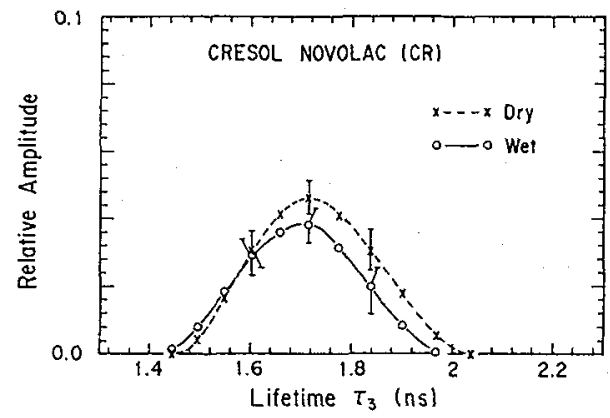

Figure $3, \tau_{3}$ of $\mathrm{CR}$

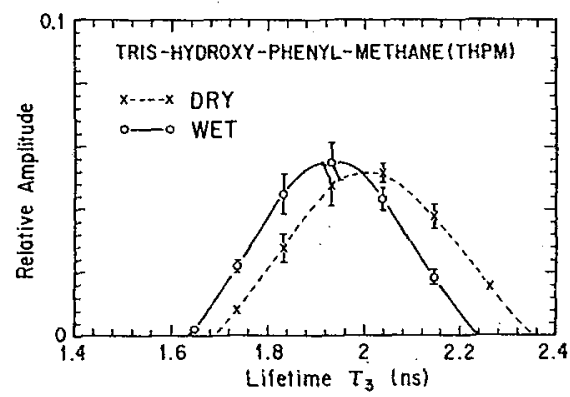

Figure $4, \tau_{3}$ of THPM

water absorption. Figures 3 and 4 show $\alpha\left(\lambda_{j}\right) \Delta \lambda_{i}$ versus $\tau \tau_{3}=1 / \lambda i$, where $\Sigma_{i} \alpha\left(\lambda_{j}\right) \Delta \lambda_{i}=1 / 4 /$. For the case of CR, two distribution patterns for dry and wet samples are similar (Fig.3) and the same results are also obtained for TMB and BA. However findings for THPM (Fig.4) show that the distribution of wet samples shift to shorter lifetimes, while the integrations of $I_{3}$ are almost the same.

\subsection{Three-dimensional hole structures}

As shown above, the distribution of $\tau_{3}$ for THPM shifts towards shorter 1 ifetimes, which seems to be related with its large $\tau_{3}$. To investigate the hole structures, a program "CSC-Chem3D" /8/ was used to calculate the smaliest unit of the three-dimensional polymer structure. The result is shown in Figure 5 .

Figure 5, A calculated three dimensional hole structure obtained for a THPM unit cel1

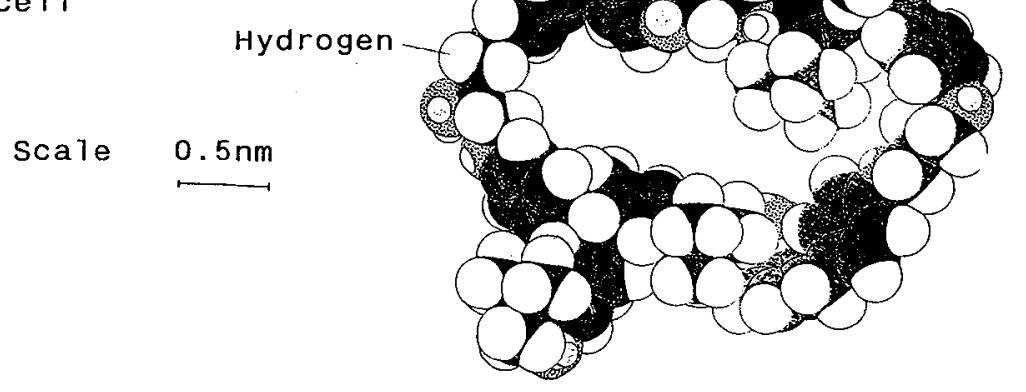


From $\tau, 3$ of POSITRONFIT, hole diameters for THPM and CR are estimated to be $0.52 \mathrm{~nm}$ and $0.58 \mathrm{~nm}$, respectively, which suggest the sma11 difference in the size: these diameters are calculated by the semi-empirical equation between $\tau_{3}$ and hole radius /9/. However, as shown in Figure 5, the hole of THPM is elitiptical in shape with much longer axis (Tong axis $\sim 1.6 \mathrm{~nm}$, short axis $\sim 0.6 \mathrm{~nm}$ ) than that of CR whose shape is quite close to sphere (long axis $\sim 1 \mathrm{~nm}$, short axis $\sim$ $0.6 \mathrm{~nm})$. $\tau{ }_{3}$ seems to be determined by the shortest distance of holes, which are similar for both CR and THPM. In the case of THPM, the shift of lifetime distribution (Fig.4) may be explained by the change in the size because of filling the holes by water molecules. Figure 1 shows the smal1 changes in $I_{3}$ for THPM but $2 \sim 3 \%$ decreases for the others. These results suggest that water molecules attached at the edge of THPM holes do not reduce the number of holes for Ps: only the size of hole becomes smaller but the hole has still enough size for Ps. In the other cases (CR, TMB, and $B A$ ), when water molecules get inside the holes, the size is not enough for $P s$, resulting in the reduction of $I_{3}$.

\section{References}

/1/T.Suzuki,Y.Oki,M.Numajiri,T.Miura,K.Kondo, Y. Ito, and Y.Shiomi J. of Appl.Polym.Science, in press

/2/P.Kirkegaard and M.Eldrup, Comp.Phy.Comm. 7( 74)401

/3/R.B: Gregory and $Y$. Zhu, Nuc1.. Instr.Meth.Phys., A290('90) 172

/4/R.B. Gregory and $Y$. Zhu, "Positron and Positronium Chemistry",p136 edited by Y.C.Jean, World Scientific ('90)

/5/R.B. Gregory, Nuc1. Instr. Meth. Phys., A302('91)496

/6/Y.C.Jean, F.Zandiehnadem and Q.Deng, Materials Science Forum 105-110('92) 1897

/7/S.W. Provencher, Comp. Phys.Comm.,27('82)213,27('82)229

/8/This program is written by Cambridge scientific computer, Inc. and the basic idea of molecular force are found in "Molecular Mechanics", by U.Burkert and N.L.Allinger, ACS, Washington D.C., ('82)

/9/H.Nakanishi and Y.C.Jean, "Positron and Positronium Chemistry" Edited by D.M.Schrader and Y.C.Jean Elsevier, Amsterdam, ('88) 